\title{
Victimization and PTSD in Ugandan Youth
}

\author{
Lise Mandrup ${ }^{1}$, Ask Elklit ${ }^{2,3 *}$ \\ ${ }^{1}$ Department of Military Psychology-The Danish Veteran Centre, Ringsted, Denmark \\ ${ }^{2}$ Danish National Center for Psychotraumatology, University of Southern Denmark, Odense, Denmark \\ ${ }^{3}$ University of Ulster, Derry, Northern Ireland \\ Email: aelklit@health.sdu.dk
}

Received 7 May 2014; revised 8 June 2014; accepted 8 July 2014

Copyright (C) 2014 by authors and Scientific Research Publishing Inc.

This work is licensed under the Creative Commons Attribution International License (CC BY).

http://creativecommons.org/licenses/by/4.0/

(c) (i) Open Access

\section{Abstract}

Background: Little is known about post-traumatic stress (PTSD) prevalence rates in community samples. This is especially true for the African continent where child-soldiers, HIV/AIDS affected and orphans have been the target for PTSD prevalence studies. Objectives: The aim of this study is to investigate the indirect and direct exposure to 20 potentially traumatic events and its relation with PTSD in a Ugandan sample of senior $3^{\text {rd }}$ year students and to perform cross-cultural comparisons with previous studies examining this age group. Socio-economic status, coping styles, negative affect, and somatization are further examined. Method: A convenience sample of 408 senior secondary school students, from eight schools, across three major towns, Kampala, Mbarara, and Jinja, were selected. The Harvard Trauma Questionnaire (HTQ) was used to establish PTSD prevalence rates, The Coping Style Questionnaire (CSQ) was used to assess coping styles, and the Trauma Symptom Checklist (TSC) were used to measure negative affect and somatization. Results: The subjects had been exposed to a mean of 6.6 direct events and a mean of 7.2 indirect events. The estimated prevalence rate of PTSD was $37.7 \%$ and a further $28.2 \%$ reached a subclinical level, missing one symptom to have the full diagnosis. Variables related to a PTSD diagnosis were female gender, number of directly experienced events, emotional coping, negative affect, and somatization. Conclusions: Ugandan youth have been exposed to significantly more potentially traumatic events and negative life events than European youth, and subsequently PTSD prevalence rates are higher. In addition, fewer gender differences are found in the Ugandan sample compared to the European samples.

\section{Keywords}

Trauma Exposure, Post-Traumatic Stress Disorder, Coping, Gender, Somatization, Negative Affectivity

\footnotetext{
${ }^{*}$ Corresponding author.
} 


\section{Victimization and PTSD in Ugandan Youth}

Despite the growing evidence that not only exposure to severe trauma (such as rape, violence, sexual abuse, and war) but also more common negative life events (such as bullying) are associated with PTSD, studies that examine a wide range of traumas and negative life events are rare. The DSM IV criteria of PTSD have hence been argued to be insufficient as also non-life threatening events or a series of “microtraumas” may precipitate PTSD [1]. Similarly, most studies on PTSD have been carried out in adult populations, despite the fact that also young children and adolescents suffer from trauma, and develop symptoms of PTSD as well as childhood trauma having lasting effects on both mental and physical health into adulthood [2].

Rather few studies have examined the prevalence of PTSD in African adolescents with the exception of studies examining the prevalence of PTSD in former child soldiers, HIV victims and orphans.

Seedat, et al. [3] examined the exposure to potentially traumatic events and PTSD in a sample of 2041 boys and girls from Grade 10 with a mean age of 15.8 in Cape Town and Nairobi. They found that $80 \%$ had been directly or indirectly exposed to severe trauma. The prevalence rate of PTSD using the Child PTSD Checklist was $22.5 \%$ in the South African sample and 5\% in the Kenyan sample while the partial-symptom PTSD was $12 \%$ and $8 \%$ respectively. Partial-symptom PTSD was defined by the authors as having at least one symptom in each DSM-IV symptom criterion category (reexperiencing, avoidance, hyperarousal). In contradiction to the aforementioned studies, Seedat et al. [3] did not find that females were at higher risk for a PTSD diagnosis. This held true for both PTSD and partial-symptom PTSD. Mels et al. [4] also examined exposure to potentially traumatic events and PTSD prevalence rates in a sample of secondary school students in the Democratic Republic of Congo. In their study, 95\% had been exposed to at least one potentially traumatic event and 52.2\% met symptom criteria for PTSD. Cumulative trauma exposure was in this study strongly associated with PTSD.

Karsberg \& Elklit [5] conducted a study in rural Kenya among 477 secondary school students with a mean age of 16.4 years. A total of $34.5 \%$ met diagnostic criteria for PTSD, with $30.5 \%$ of boys and $42.3 \%$ of girls meeting PTSD criteria. Another study, also from Kenya, examined PTSD prevalence rates among impoverished youth and found that $18 \%$ met criteria for PTSD after screening. However, after conducting clinical diagnostic interviews only $12 \%$ reached diagnostic criteria [6]. It hence appears that the overall exposure to potentially traumatic events and subsequent PTSD are significantly higher in the studied populations of African adolescents compared to European adolescents [7]-[10]. However, the substantial variations in prevalence rates within countries warrant for caution in making generalizations.

In Uganda, most studies on prevalence rates of PTSD have focused exclusively on former child soldiers and internally displaced people. One study of 169 former Ugandan and Congolese child soldiers with a mean age of 15.2 years found the prevalence rate of PTSD to be $34.9 \%$ as measured by the Child Post Traumatic Stress Disorder Reaction Index (CPTSD-RI; [11]). In one comparative study of abducted and non-abducted adolescents living in Gulu district, prevalence rates of PTSD were 26.8\% for abductees and 12.6\% for non-abducted adolescents [12].

The current study was designed to provide epidemiological information about exposure to traumatic events and negative life events (e.g. parental divorce or being bullied), and the prevalence of PTSD among Ugandan senior $3^{\text {rd }}$ year students. The study replicates previous European studies of the same age groups [7]-[10], one Indian study [13], and one Kenyan Study [5].

There is an ongoing debate whether the PTSD diagnosis transcends cultures, but a growing number of research studies support the application of the DSM-IV criteria for PTSD to go beyond culture [14] [15]. Uganda is an East African country with borders to Kenya, Tanzania, Rwanda, Democratic Republic of Congo and Sudan. Most of the country has experienced a relative long period of stability after National Resistance Movement (NRM) took over power in 1986. Some areas of Uganda, have, however had armed conflicts since. The total population of Uganda is 34.1 million of which $56.1 \%$ are eighteen and below. The average life expectancy is 54 years. One quarter of the Ugandans are considered poor [16]. To our knowledge the current study is the only one examining the prevalence rate of PTSD in young Ugandans who have not been directly involved in armed conflict or lives in areas affected by armed conflict.

Lazarus and Folkman [17] describe coping as a product of the interaction between situation-specific characteristics and personal resources. Identifying correlates of coping in adolescence may be especially important because adolescents are confronted with many new life stressors for which they have not yet developed a repertoire of coping responses to draw from [18]. Associations between personality and coping appear to be stronger 
for younger samples [19], suggesting that personality may be particularly important in predicting coping in adolescents. Research into coping styles has mostly focused on problem-focused and emotion-focused coping [17]. Problem-focused coping aimed at changing the stressor is generally considered adaptive. In contrast, emotion-focused coping aimed at changing one's own emotional responses to the stressor is viewed as maladaptive and has been linked to poor psychological health in adolescents [20]. Furthermore, problem-focused coping has been found to be either not associated with posttraumatic symptomatology or to serve as a protective factor following different types of traumatic exposure, whereas emotion-focused coping has been found to correlate with increased posttraumatic symptomatology [21].

Negative affectivity refers to a mood dimension and reflects a general tendency to react to and have a negative perspective on the surrounding world and oneself [22]. Negative affectivity can either be seen as a state or as a personality factor similar to neuroticism. Significant associations between PTSD and negative affectivity are found in relation to trauma exposed adolescents [23]. Somatization refers to the development of somatic symptoms for which no organic cause is found [24] [25]. The low prevalence of somatization in study samples has led researchers to use the less restrictive concept of somatization. Somatization is often considered to represent a continuum with few symptoms at one end and multiple symptoms relating to various body sites at the other [26]. Somatoform symptoms have consistently been linked to traumatic exposure. Trauma victims tend to score higher on self-reports of somatic complaints compared to controls [23].

It is expected that the Ugandan adolescents have experienced more potentially traumatic events and negative life events than what has been found in adolescent samples in European countries. Hence a higher prevalence rate of PTSD is expected among young Ugandans. It is expected that female gender, family poverty, low parental education level, and high degree of exposure to potential trauma and negative life events, will be associated with higher degree of PTSD severity. We also expect emotional coping, negative affectivity, and somatization to be positively associated with PTSD symptoms.

\section{Method}

\subsection{Procedures}

Before conducting the study, an application explaining the aim of the study, the procedures, the confidentiality principles, alongside with the questionnaire was sent to the Ugandan National Council for Science and Technology who approved the study. After the approval, a meeting with the headmasters of the selected schools was held where the aim of the study and the confidentiality principles was explained. Before commencing on the study, a pilot study was conducted were the students were given the questionnaires in the classroom and asked to independently fill it out. All the questionnaires were in English which is the official language of the country and the school system in Uganda. At this school level (senior three) we expected very few students asked for help to have a word explained. However, it quickly became apparent that the students had some language difficulties and because of these difficulties had questions to an extent that did not make it possible to answer each student individually. As a consequence the procedure in the study was changed, so that the whole class answered all questions simultaneously. This made it possible to answer questions without exceeding a reasonable time frame. Before handing out the questionnaires to the students, a short introduction was given, explaining the purpose of the study, the option of not participating, the confidentiality principles and the procedure of collecting the questionnaire in one envelope and sealing it in front of the students. It took approximately 1.5 hours for the students to fill in the questionnaires.

\subsection{Measures}

The first part of the questionnaire concerned age, gender, tribe, living arrangements (living with one or both parents or others such as an aunt or in an institution etc.) and socioeconomic status. As studies have shown that adolescents knowledge of their parents income and occupational status is not very reliable [27], the parents level of education, number of assets in the household (bicycle, running water, electricity, car, and TV), the number of people sleeping in the same room in the household, and the number of full meals per day was used as a crude measure of socioeconomic status.

The second part of the questionnaire contained a list of 20 potentially traumatizing events and negative life events. The students were asked to indicate whether they had had no exposure, direct exposure, or indirect ex- 
posure (witnessing the event or having someone very close to them experience the event) to each of the listed events. The 20 potentially traumatic events were selected from scientific literature and clinical experience. The list covered possible life-threatening experiences and distressing family conditions including pregnancy/abortion, parents' divorce, severe childhood neglect and absence of a parent, as well as other negative events.

The Coping Style Questionnaire (CSQ) [28] [29] which consists of 37 questions was used to measure coping styles. The 37 items were scored on a 4 point Likert scale where the students were asked to indicate to what extent they reacted to stress in the described manner $(1=$ never, $2=$ sometimes, $3=$ often, $4=$ always $)$. The internal consistency of the scale was questionable with a Cronbach's alpha of 0.59 for rational coping and 0.61 for emotional coping.

The Harvard Trauma Questionnaire-Part IV (HTQ) was used to estimate the occurrence of PTSD in the time following the most distressing event as chosen by the student [30]. The HTQ consist of 31 items where 17 are directly associated with the diagnostic criteria of PTSD and measure the intensity of the three core symptoms of the PTSD diagnosis, re-experiencing, avoidance, and arousal (DSM IV-TR; [31]). The 31 items were scored on a 4 point Likert scale where the students were asked to indicate to which extend the symptoms had bothered them in the past ( $1=$ not at all, $2=$ a little, $3=$ quite a bit, $4=$ extremely). The internal consistency of the scale was good with Cronbach's alpha at 0.86 for the total scale HTQ.

The Trauma Symptom Checklist (TSC; [32]) were used to measure degrees of negative affect and somatization [33]. It consist of 32 questions and is measured on a 4 point Likert scale were the students was asked to indicate how often during the last month they had experienced the symptoms $(1=$ not at all, $2=$ sometimes, $3=$ often, $4=$ always). The scale showed good internal consistency with a Cronbach's Alpha of 0.80 for the total scale and 0.72 for negative affect and 0.62 for somatization.

\subsection{Participants}

The data was collected among 408 senior three students aged $13-24$ years $(M=15.95 ; S D=1.377)$ in eight schools across three major towns, Kampala (the capital, located in central Uganda), Mbarara (Western Uganda) and Jinja (Eastern Uganda). The gender distribution was 49.8\% males and 50.2\% females.

\section{Results}

\subsection{Socioeconomic Status}

Of the total sample, $42.2 \%$ lived with both parents, 35.3\% lived with a single parent, and $22.3 \%$ had other arrangements, and $0.2 \%$ did not state living arrangements. Of the total sample, $95.8 \%$ stated their father's education and $89.7 \%$ stated their mother's education. The fathers' versus the mother' educational level was respectively: no formal education $13.5 \%$ versus $14.7 \%$, Primary school (7 years) $15.7 \%$ versus $20.6 \%$, Secondary school (13 years) $27.5 \%$ versus $29.4 \%$, Diploma (2 years after finishing secondary) $16.7 \%$ versus $13.7 \%$, Bachelor's degree ( 3 years after finishing secondary) $10.5 \%$ versus $6.1 \%$, Master's degree $12 \%$ versus $5.1 \%$. With regards to how many people shared the same bedroom $6.1 \%$ had their own bedroom, $24.8 \%$ shared their bedroom with one person, $17.4 \%$ shared their bedroom with two other people, $16.4 \%$ shared their bedroom with three other people, $14 \%$ shared their bedroom with four other people, $11.5 \%$ shared their bedroom with 5 other people, $8.8 \%$ shared their room with 6 or more other people. One percent did not state with how many they shared their bedroom with.

Of the subjects, $14 \%$ reported living of one meal a day, $46.3 \%$ lived of two meals a day and $38.2 \%$ lived of three meals a day. One and a half percent did not state how many meals they had a day. With regards to assets 4.4\% had no assets from the list, $14.5 \%$ had one asset, $15.2 \%$ had two assets, $29.9 \%$ had three assets, $19.6 \%$ had four assets and $16.4 \%$ had all five assets from the list.

\subsection{Exposure to Potentially Traumatic Events and PTSD}

Of the total sample of 408 senior three students, $97.8 \%$ reported having experienced at least one potentially traumatic event. The average number of directly experienced and indirectly experienced events per student was 6.6 and 7.2 respectively. No significant gender differences were found in respect to average number of events experienced. Of the total sample $61.3 \%$ of the students had experienced at least one potentially traumatic event within the last year. 
The most commonly reported events were death of someone close (75.5\%), serious illness (65.9\%), bullying (52.9\%), physical abuse (51\%), and physical assault (48\%). The least reported events were severe childhood neglect (25.7\%), suicide attempt (17.6\%), sexual abuse (15\%), rape (6.9\%), and pregnancy/abortion (6.4\%). Table 1 shows the gender differences between direct and indirect exposure to the 20 potentially traumatic events. More females than males had been raped $\left(X^{2}(1,407)=12.44 ; p<0.0005\right)$, suffered childhood neglect $\left(X^{2}(1,407)\right.$ $=7.27 ; p<0.005)$ and had experienced absence of a parent more frequent than males $\left(X^{2}(1,407)=7.27 ; p<\right.$ 0.005). There were no gender differences with regard to indirect exposure.

On the scale measures, there were very few missing values $(0.2 \%$ to $4 \%)$; due to the large sample size no compensation for missing values was performed. Of the total sample $37.7 \%$ fulfilled the criteria for a PTSD diagnosis. The gender distribution was $44.4 \%$ of the females and $31 \%$ of the males that met the diagnostic criteria for PTSD. A further $28.2 \%$ of the total sample constituted a subclinical group. Of the children who lived with both parents, 31.4 percent met diagnostic criteria for PTSD, of the children living with one parent $37.5 \%$ met diagnostic criteria for PTSD, and finally the children who had other living arrangements almost half (49.5\%) met diagnostic criteria for PTSD.

Table 1. Direct and indirect trauma exposure by gender.

\begin{tabular}{|c|c|c|c|c|c|c|}
\hline \multirow[b]{2}{*}{ Event } & \multicolumn{3}{|c|}{ Direct exposure } & \multicolumn{3}{|c|}{ Indirect exposure } \\
\hline & $\begin{array}{c}\text { Percent } \\
\text { females }(n=205)\end{array}$ & $\begin{array}{l}\text { Percent males } \\
\quad(\mathrm{n}=203)\end{array}$ & $\begin{array}{l}\text { Percent all } \\
(\mathrm{n}=408)\end{array}$ & $\begin{array}{l}\text { Percent females } \\
\quad(\mathrm{n}=205)\end{array}$ & $\begin{array}{l}\text { Percent males } \\
\quad(\mathrm{n}=203)\end{array}$ & $\begin{array}{l}\text { Percent all } \\
(\mathrm{n}=408)\end{array}$ \\
\hline Traffic accident & 30.7 & 26.1 & 28.4 & 62.9 & 62.6 & 62.7 \\
\hline Other serious accident & 32.2 & 32 & 32.1 & 50.7 & 52.7 & 51.7 \\
\hline Physical assault & 50.2 & 45.8 & 48 & 35.1 & 38.9 & 37 \\
\hline Rape & 11.2 & 2.5 & $6.9^{* * *}$ & 29.3 & 22.2 & 25.7 \\
\hline $\begin{array}{l}\text { Witnessed other people } \\
\text { being injured or killed }\end{array}$ & 45.8 & 42 & 43.9 & 44.9 & 39.9 & 42.4 \\
\hline Being close to be injured or killed & 45.9 & 46.3 & 46.1 & 37.6 & 37.9 & 37.7 \\
\hline Threats of violence & 38.5 & 38.9 & 38.7 & 38.5 & 41.9 & 40.2 \\
\hline Near-drowning & 30.7 & 32.5 & 31.6 & 28.8 & 36.9 & 32.8 \\
\hline Suicide attempt & 20.5 & 14.8 & 17.6 & 23.4 & 25.6 & 24.5 \\
\hline Robbery/theft & 44.9 & 41.9 & 43.4 & 44.9 & 42.4 & 43.6 \\
\hline Pregnancy/abortion & 7.8 & 4.9 & 6.4 & 31.2 & 32 & 31.6 \\
\hline Serious illness & 67.8 & 64 & 65.9 & 57.6 & 53.2 & 55.4 \\
\hline Death of someone close & 78 & 72.9 & 75.5 & 54.1 & 51.7 & 52.9 \\
\hline Parents' divorce & 29.8 & 23.6 & 26.7 & 28.8 & 35 & 31.9 \\
\hline Sexual abuse & 18.5 & 11.3 & 15 & 29.3 & 27.6 & 28.4 \\
\hline Physical abuse & 55.1 & 46.8 & 51 & 34.1 & 40.9 & 37.5 \\
\hline Severe childhood neglect & 30.7 & 20.7 & $25.7^{*}$ & 39.5 & 41.9 & 40.7 \\
\hline Bullying & 49.8 & 56.2 & 52.9 & 46.8 & 46.3 & 46.6 \\
\hline Absence of a parent & 51.7 & 38.4 & $45.1^{* *}$ & 40.5 & 42.9 & 41.7 \\
\hline Other & 8.8 & 12.8 & 10.8 & 5.4 & 5.9 & 5.6 \\
\hline
\end{tabular}

$*=p<0.05, * *=p<0.005, * * *=p<0.0005$. 


\subsection{Correlations between SES Measures and Measures of PTSD}

The relationship between the measures for socioeconomic status was evaluated using the Pearson correlation coefficient (Table 2). There were significant correlations between most of the SES measures. Parental education was associated with fewer sleeping in the same bedroom, more daily meals, and more assets.

With regards to coping styles, no significant correlations between SES measures and rational coping were found. Emotional coping on the other hand was negatively correlated with number of meals, number of assets, parental educational level, and positively correlated with number of persons sharing the same bedroom. None of the SES measures correlated with number of indirect events experienced but the exposure to direct events correlated negatively with number of meals, and number of assets. With regard to total TSC score and the subscales (somatization and negative affect), no correlations with SES measures was found. Total HTQ was related to one SES measure, the number of persons sharing the same room.

\subsection{Correlations between Exposure, Coping Styles, Negative Affect, Somatization, and PTSD Scores}

The relationship between the measures for exposure, coping styles, negative affect, somatization and PTSD was evaluated using the Pearson correlation coefficient (Table 2). Positive correlations were found between indirect and direct exposure.

The number of direct events experienced was correlated with emotional coping, TSC total, negative affect, somatization, and total HTQ score. The number of indirect events experienced was positively correlated with emotional coping, total TSC, negative affect, somatization, and total HTQ.

Table 2. Correlations between SES, coping styles, exposure, negative affect, somatization and PTSD.

\begin{tabular}{|c|c|c|c|c|c|c|c|c|c|c|c|c|c|}
\hline $\mathrm{N}=408$ & 1) & 2) & 3) & 4) & 5) & $6)$ & 7) & 8) & 9) & 10) & $11)^{\mathrm{A}}$ & $12)^{\mathrm{A}}$ & 13) \\
\hline 1) Age & 1 & & & & & & & & & & & & \\
\hline 2) Meals & $\begin{array}{c}05 \\
0.35\end{array}$ & 1 & & & & & & & & & & & \\
\hline 3) Rooms & $\begin{array}{c}-0.14^{* *} \\
0.01\end{array}$ & $\begin{array}{c}-0.11^{*} \\
0.03\end{array}$ & 1 & & & & & & & & & & \\
\hline 4) Assets & $\begin{array}{c}-0.10 \\
0.05\end{array}$ & $\begin{array}{c}0.35^{* *} \\
0.00\end{array}$ & $\begin{array}{c}-0.16^{* *} \\
0.00\end{array}$ & 1 & & & & & & & & & \\
\hline 5) Fathers' education & $\begin{array}{c}-0.02 \\
0.69\end{array}$ & $\begin{array}{c}0.25^{* *} \\
0.00\end{array}$ & $\begin{array}{c}-0.11^{*} \\
0.03\end{array}$ & $\begin{array}{c}0.31^{* *} \\
0.00\end{array}$ & 1 & & & & & & & & \\
\hline 6) Mothers' education & $\begin{array}{c}-0.08 \\
0.12\end{array}$ & $\begin{array}{c}0.18^{* *} \\
0.00\end{array}$ & $\begin{array}{c}-0.14^{* *} \\
0.01\end{array}$ & $\begin{array}{c}0.26^{* *} \\
0.00\end{array}$ & $\begin{array}{c}0.48^{* *} \\
0.00\end{array}$ & 1 & & & & & & & \\
\hline 7) Emotionel coping & $\begin{array}{c}-0.04 \\
0.46\end{array}$ & $\begin{array}{c}-0.16^{* *} \\
0.00\end{array}$ & $\begin{array}{c}0.10^{*} \\
0.04\end{array}$ & $\begin{array}{c}-0.11^{*} \\
0.03\end{array}$ & $\begin{array}{c}-0.13^{*} \\
0.01\end{array}$ & $\begin{array}{c}-0.12^{*} \\
0.01\end{array}$ & 1 & & & & & & \\
\hline 8) Rational coping & $\begin{array}{l}0.09 \\
0.06\end{array}$ & $\begin{array}{c}-0.03 \\
0.61\end{array}$ & $\begin{array}{l}0.02 \\
0.68\end{array}$ & $\begin{array}{c}-0.03 \\
0.61\end{array}$ & $\begin{array}{l}0.02 \\
0.72\end{array}$ & $\begin{array}{l}0.03 \\
0.57\end{array}$ & $\begin{array}{l}0.09 \\
0.07\end{array}$ & 1 & & & & & \\
\hline 9) Total indirect events & $\begin{array}{c}-0.09 \\
0.07\end{array}$ & $\begin{array}{c}-0.04 \\
0.44\end{array}$ & $\begin{array}{c}-0.07 \\
0.13\end{array}$ & $\begin{array}{c}-0.02 \\
0.76\end{array}$ & $\begin{array}{c}-0.02 \\
0.65\end{array}$ & $\begin{array}{c}-0.03 \\
0.53\end{array}$ & $\begin{array}{c}0.16^{*} \\
0.00\end{array}$ & $\begin{array}{l}0.05 \\
0.27\end{array}$ & 1 & & & & \\
\hline 10) Total direct events & $\begin{array}{c}-0.00 \\
0.99\end{array}$ & $\begin{array}{c}-0.14^{* *} \\
0.00\end{array}$ & $\begin{array}{l}0.08 \\
0.09\end{array}$ & $\begin{array}{c}-0.16^{* *} \\
0.00\end{array}$ & $\begin{array}{c}-0.10 \\
0.05\end{array}$ & $\begin{array}{c}-0.03 \\
0.49\end{array}$ & $\begin{array}{c}0.22^{* *} \\
0.00\end{array}$ & $\begin{array}{l}0.09 \\
0.07\end{array}$ & $\begin{array}{c}0.35^{* *} \\
0.00\end{array}$ & 1 & & & \\
\hline 11) TSC total ${ }^{\mathrm{A}}$ & $\begin{array}{l}0.01 \\
0.91\end{array}$ & $\begin{array}{c}-0.02 \\
0.75\end{array}$ & $\begin{array}{l}0.05 \\
0.32\end{array}$ & $\begin{array}{c}-0.07 \\
0.15\end{array}$ & $\begin{array}{c}-0.06 \\
0.21\end{array}$ & $\begin{array}{c}-0.06 \\
0.20\end{array}$ & $\begin{array}{c}0.43^{* *} \\
0.00\end{array}$ & $\begin{array}{c}0.13^{* *} \\
0.01\end{array}$ & $\begin{array}{c}0.18^{* *} \\
0.00\end{array}$ & $\begin{array}{c}0.31^{* *} \\
0.00\end{array}$ & 1 & & \\
\hline 12) TSC negative affect ${ }^{A}$ & $\begin{array}{l}0.03 \\
0.62\end{array}$ & $\begin{array}{l}0.01 \\
0.79\end{array}$ & $\begin{array}{l}0.05 \\
0.28\end{array}$ & $\begin{array}{c}-0.08 \\
0.11\end{array}$ & $\begin{array}{c}-0.08 \\
0.10\end{array}$ & $\begin{array}{c}-0.10 \\
0.05\end{array}$ & $\begin{array}{c}0.43^{* *} \\
0.00\end{array}$ & $\begin{array}{c}0.17^{* *} \\
0.00\end{array}$ & $\begin{array}{c}0.16^{* *} \\
0.00\end{array}$ & $\begin{array}{c}0.28^{* *} \\
0.00\end{array}$ & $\begin{array}{c}0.93^{* *} \\
0.00\end{array}$ & 1 & \\
\hline 13) TSC somatization & $\begin{array}{c}-0.02 \\
0.67\end{array}$ & $\begin{array}{c}-0.05 \\
0.28\end{array}$ & $\begin{array}{l}0.03 \\
0.49\end{array}$ & $\begin{array}{c}-0.04 \\
0.38\end{array}$ & $\begin{array}{c}-0.03 \\
0.61\end{array}$ & $\begin{array}{c}-0.00 \\
0.94\end{array}$ & $\begin{array}{c}0.34^{* *} \\
0.00\end{array}$ & $\begin{array}{l}0.07 \\
0.19\end{array}$ & $\begin{array}{c}0.17^{* *} \\
0.00\end{array}$ & $\begin{array}{c}0.27^{* *} \\
0.00\end{array}$ & $\begin{array}{c}0.87^{* *} \\
0.00\end{array}$ & $\begin{array}{c}0.64^{* *} \\
0.00\end{array}$ & 1 \\
\hline 14) Total HTQ & $\begin{array}{c}-0.05 \\
0.33\end{array}$ & $\begin{array}{c}-0.09 \\
0.06\end{array}$ & $\begin{array}{c}0.13^{* * *} \\
0.01\end{array}$ & $\begin{array}{c}-0.09 \\
0.08\end{array}$ & $\begin{array}{c}-0.07 \\
0.19\end{array}$ & $\begin{array}{c}-0.09 \\
0.08\end{array}$ & $\begin{array}{c}0.41^{* *} \\
0.00\end{array}$ & $\begin{array}{l}0.09 \\
0.07\end{array}$ & $\begin{array}{c}0.20^{* *} \\
0.00\end{array}$ & $\begin{array}{c}0.31^{* *} \\
0.00\end{array}$ & $\begin{array}{c}0.52^{* *} \\
0.00\end{array}$ & $\begin{array}{c}0.49^{* *} \\
0.00\end{array}$ & $\begin{array}{c}0.44^{* *} \\
0.00\end{array}$ \\
\hline
\end{tabular}

Note: ${ }^{*}$ Correlation is significant at the 0.05 level (2-tailed). ${ }^{* *}$ Correlation is significant at the 0.01 level (2-tailed). ${ }^{A} n=407$. 
With regards to coping styles it was found that rational coping correlated positively with total TSC scores and negative affect. Emotional coping correlated positively with total TSC score, negative affect, somatization and total HTQ. The TSC scores all correlated positively with total HTQ score TSC total, negative affect, and somatization.

\subsection{Gender Differences and Differences in Living Arrangements in Regards to TSC and HTQ Scores}

To reduce the probability of making type 1 errors among the hypotheses, a Holm-Bonferroni correction of $(0.05 / 3=0.0167)$ was made. Students who lived with none of their parents had experienced significantly more negative life events than children living with one or both parents $(F(2,404)=14.2 ; p<0.0005)$. Similarly a significantly higher total HTQ score was found among students who did not live with either parent compared to students who live with one or both parents $(F(2,404)=4.95 ; p<0.008)$. With regard to negative affect students who did not live with either parent experienced more negative affect compared to students who only lived with one or both parents $(F(2,403)=3.79 ; p<0.05)$. Females had a significantly higher total HTQ and TSC score compared to males $(F(1,406)=14.66 ; p<0.0005)(F(1,405)=6.52 ; p<0.01)$ respectively. Likewise females reported higher levels of negative affect and somatization compared to males $(F(1,405)=5.23 ; p<0.05)$, $F(1,406)=5.76 ; p<0.02)$ respectively.

\subsection{Regression Analysis}

Regression analysis was carried out to see which specific traumatic events were significantly related to PTSD symptomatology. Five direct events were significantly related to PTSD symptomatology (Table 3); traffic accident, threats of violence, sexual abuse, severe childhood neglect, and bullying. Traffic accidents have a negative relationship to PTSD severity, in contrast to the others which had a positive relationship to PTSD severity. Six indirect traumatic events was also related to PTSD symptomatology (Table 4); serious accident, near drowning, and physical abuse had a negative association, while rape, witnessing people injured or killed, severe childhood neglect, and bullying had a positive relationship to PTSD severity.

Table 3. Regression analysis for direct events with HTQ total as the dependent variable.

\begin{tabular}{|c|c|c|c|c|c|}
\hline \multirow{2}{*}{ Model } & \multicolumn{2}{|c|}{ Unstandardized coefficients } & \multirow{2}{*}{$\begin{array}{c}\text { Standardized coefficients } \\
\text { Beta }\end{array}$} & \multirow{2}{*}{$\mathrm{t}$} & \multirow{2}{*}{ sig } \\
\hline & $\mathrm{B}$ & Std. error & & & \\
\hline (Constant) & 60.56 & 1.93 & & 31.37 & 0.00 \\
\hline Traffic accident & -4.18 & 1.66 & -0.12 & -2.52 & 0.01 \\
\hline Other serious accident & -1.51 & 1.65 & -0.05 & -0.92 & 0.36 \\
\hline Physical assault & 0.80 & 1.58 & 0.03 & 0.51 & 0.61 \\
\hline Rape & 0.56 & 2.98 & 0.01 & 0.19 & 0.85 \\
\hline Witnessed other people being injured or killed & 1.67 & 1.57 & 0.05 & 1.06 & 0.29 \\
\hline Being close to be injured or killed & 1.74 & 1.51 & 0.06 & 1.15 & 0.25 \\
\hline Threats of violence & 4.13 & 1.62 & 0.13 & 2.55 & 0.01 \\
\hline Near-drowning & 1.46 & 1.65 & 0.04 & 0.89 & 0.38 \\
\hline Suicide attempt & 3.26 & 1.98 & 0.08 & 1.64 & 0.10 \\
\hline Robbery/theft & -0.96 & 1.52 & -0.03 & -0.63 & 0.53 \\
\hline Pregnancy/abortion & -1.22 & 3.26 & -0.02 & -0.37 & 0.71 \\
\hline Serious illness & 2.21 & 1.66 & 0.07 & 1.33 & 0.18 \\
\hline Death of someone close & 0.42 & 1.76 & 0.01 & 0.24 & 0.81 \\
\hline Parents’ divorce & 0.03 & 1.82 & 0.00 & 0.02 & 0.99 \\
\hline Sexual abuse & 4.50 & 2.27 & 0.10 & 1.98 & 0.05 \\
\hline Physical abuse & 0.75 & 1.63 & 0.02 & 0.46 & 0.65 \\
\hline Severe childhood neglect & 5.34 & 1.89 & 0.15 & 2.83 & 0.01 \\
\hline Bullying & 4.03 & 1.56 & 0.13 & 2.59 & 0.01 \\
\hline Absence of a parent & 2.20 & 1.60 & 0.07 & 1.37 & 0.17 \\
\hline
\end{tabular}


Table 4. Regression analysis for indirect events with HTQ total as the dependent variable.

\begin{tabular}{|c|c|c|c|c|c|}
\hline \multirow{2}{*}{ Model } & \multicolumn{2}{|c|}{ Unstandardized coefficients } & \multirow{2}{*}{$\begin{array}{c}\text { Standardized coefficients } \\
\text { Beta }\end{array}$} & \multirow{2}{*}{$\mathrm{T}$} & \multirow{2}{*}{ Sig } \\
\hline & B & Std. error & & & \\
\hline (Constant) & 66.24 & 1.49 & & 44.58 & 0.00 \\
\hline Traffic accident & -0.18 & 1.69 & -0.01 & -0.11 & 0.92 \\
\hline Other serious accident & -3.58 & 1.62 & -0.12 & -2.21 & 0.03 \\
\hline Physical assault & 1.88 & 1.71 & 0.06 & 1.10 & 0.27 \\
\hline Rape & 4.73 & 1.87 & 0.13 & 2.54 & 0.01 \\
\hline Witnessed other people being injured or killed & 4.68 & 1.77 & 0.15 & 2.64 & 0.01 \\
\hline Being close to be injured or killed & 0.94 & 1.87 & 0.03 & 0.50 & 0.62 \\
\hline Threats of violence & 0.24 & 1.76 & 0.01 & 0.14 & 0.89 \\
\hline Near-drowning & -3.88 & 1.82 & -0.12 & -2.14 & 0.03 \\
\hline Suicide attempt & 2.45 & 1.97 & 0.07 & 1.24 & 0.22 \\
\hline Robbery/theft & -1.70 & 1.80 & -0.05 & -0.95 & 0.35 \\
\hline Pregnancy/abortion & 1.12 & 1.87 & 0.03 & 0.60 & 0.55 \\
\hline Serious illness & -0.02 & 1.93 & -0.00 & -0.01 & 0.99 \\
\hline Death of someone close & -0.67 & 1.82 & -0.02 & -0.37 & 0.71 \\
\hline Parents' divorce & 1.52 & 1.84 & 0.05 & 0.82 & 0.41 \\
\hline Sexual abuse & -1.24 & 2.05 & -0.04 & -0.61 & 0.55 \\
\hline Physical abuse & -4.76 & 1.90 & -0.15 & -2.51 & 0.01 \\
\hline Severe childhood neglect & 4.10 & 1.81 & 0.13 & 2.27 & 0.02 \\
\hline Bullying & 8.76 & 1.85 & 0.28 & 4.75 & 0.00 \\
\hline Absence of a parent & -2.33 & 1.78 & -0.08 & -1.31 & 0.19 \\
\hline
\end{tabular}

\subsection{Hierarchal Regression Analysis}

In order to examine the effects of age, gender, SES measures, experienced events, coping styles and somatization and negative affect on PTSD symptomatology, a hierarchal regression analysis was carried out. Age, gender, and SES measures (parents educational level, living arrangements, number of meals, number of assets and number of people sharing bedroom) were entered at Step 1, explaining 7\% of the variance in PTSD symptomatology. Step 2 included indirect and direct exposure to potentially traumatic events. After Step 2, 16.5\% of the variance in PTSD symptomatology could be explained. After the entry of rational coping and emotional coping in Step 3, 23\% of the variance in PTSD symptomatology could be explained. Last step included somatization and negative affect at which $34 \%$ of the variance in PTSD symptomatology could be explained.In the final model (Table 5), only gender, direct exposure, emotional coping, negative affect, and somatization were statistically significant.

\section{Discussion}

\subsection{Gender Differences}

There were relatively few gender differences with regards to type of exposure to potentially traumatic events, compared to Western studies where males more often than females are exposed to violent traumas [34]-[36]. This was not the case for Uganda with males and females experiencing violent trauma to the same extent. Not surprisingly, and in line with an array of research [34] more girls than boys had been raped. Interestingly, in the 
Table 5. Hierarchal regression analysis with HTQ total as the dependent variable.

\begin{tabular}{|c|c|c|c|c|c|}
\hline \multirow{2}{*}{ Model } & \multicolumn{2}{|c|}{ Unstandardized coefficients } & \multirow{2}{*}{$\begin{array}{c}\text { Standardized coefficients } \\
\text { Beta }\end{array}$} & \multirow{2}{*}{$\mathrm{T}$} & \multirow{2}{*}{ Sig } \\
\hline & B & Std. error & & & \\
\hline Constant & 21.31 & 11.30 & & 1.89 & 0.06 \\
\hline Age & -0.09 & 0.53 & -0.01 & -0.16 & 0.87 \\
\hline Gender & 4.69 & 1.43 & 0.15 & 3.27 & 0.001 \\
\hline Number of assets & 0.09 & 0.55 & 0.01 & 0.16 & 0.88 \\
\hline Living conditions & -0.34 & 0.93 & -0.02 & -0.37 & 0.71 \\
\hline Number of meals & -0.56 & 1.11 & -0.03 & -0.50 & 0.62 \\
\hline Sharing bedroom & 0.58 & 0.40 & 0.07 & 1.44 & 0.15 \\
\hline Fathers' education & -0.00 & 0.64 & 0.00 & -0.01 & 1.00 \\
\hline Mothers' education & -0.44 & 0.73 & -0.04 & -0.61 & 0.54 \\
\hline Direct events & 0.69 & 0.24 & 0.15 & 2.90 & 0.005 \\
\hline Indirect events & 0.23 & 0.16 & 0.07 & 1.50 & 0.13 \\
\hline Rational coping & 0.07 & 0.13 & 0.03 & 0.56 & 0.58 \\
\hline Emotional coping & 0.45 & 0.16 & 0.14 & 2.81 & 0.005 \\
\hline Negative affect & 0.71 & 0.15 & 0.28 & 4.65 & 0.0005 \\
\hline Somatization & 0.41 & 0.20 & 0.12 & 2.09 & 0.04 \\
\hline
\end{tabular}

Note: Adjusted $\mathrm{R}^{2}=0.34$.

current study, girls more often than boys experienced severe childhood neglect and the absence of a parent. One of the explanations for this could be the value that culturally is being put on having boys. It could be speculated that the father would be more likely to leave the family if a boy was not born.

An explanation for the few gender differences with regards to exposure might be accounted for by the level of exposure being so high that the risk behavior of males that normally accounts for the difference of exposure is not applicable in low income countries with high incident rates of violence. This would also explain why there was no gender differences found in indirect exposure. O’Donnell, et al. [37] examined the gender differences to exposure and PTSD in a Gambian senior school population (mean age of 17.8) and similarly found no gender differences with regards to level of exposure to traumatic events.

In line with previous findings it was found that females are at greater risk for developing a PTSD diagnosis than males: $44.4 \%$ females vs. $31 \%$ males. Likewise, females more often than males experienced negative affect and somatization. Interestingly and not in accordance with previous studies where women used more emotional and men more rational coping styles [38]-[40], there were no gender differences in regards to coping styles with males and females using emotional and rational coping styles equally.

\subsection{Living Conditions, Exposure and Support}

The adolescents in the current study, who was not living with either parent, had experienced significantly more potentially traumatic events than adolescents who lived with one or both parents, and subsequently, suffered from PTSD more often (49.5\% vs. $37.5 \%$ vs. $31.4 \%)$ respectively. It is further well-documented that social support after a traumatic experience is crucial to whether or not PTSD is subsequently developed [41]-[43]. It is hence proposed that children living without either parent are at double risk in that it is expected that they will live in more deprived settings and engage more easily in behaviors leading to more exposure and it is expected that the social support after exposure will be less.

Similarly, children who lived with neither parent experienced more negative affect than children living with one or both parents. The correlations between negative affect and absence of a parent could be mediated by the 
lack of or low perceived social support which research shows is a risk factor. Siedlecki, et al. [44] examined the role of perceived support and found that lack hereof correlated positively with negative affect. Similarly in a cross cultural study [45], it was found that in USA, Jordan, and Iran low perceived social support from family correlated with negative affect across all cultures. It was only in the US that there were correlations between low perceived social support from friends and negative affect, highlighting the importance of the family in more collectivistic cultures such as that of Uganda. Other studies have similarly established a connection between low social support and negative affect [46].

No differences were found with regards to coping styles and somatization in relation to living conditions. The current study is hence in line with previous studies emphasizing the importance of social support after a traumatic event as well as social support as a buffer against engaging in high risk behaviors.

\subsection{Cross Cultural Comparison of Direct Exposure to Potentially Traumatic Events and Development of PTSD}

The present study showed that $97.8 \%$ of the students in the Ugandan sample had been directly exposed to at least one potentially traumatic event. The students had experienced a mean of 6.6 potentially traumatic events compared to a mean of 1.9 - 3.1 potentially traumatic events in the similar European studies [7]-[10]. Thus, as expected, the percentage of senior $3^{\text {rd }}$ year students' exposure to potentially traumatic events was more than twice as high in the Ugandan sample. In line with the significant higher exposure to traumatic events, in the Ugandan sample, a 2 - 3 times higher rate of PTSD was found compared to the European studies, where between $6 \%$ and $20 \%$ in the same age group meet criteria for PTSD whereas the number was $37.7 \%$ in the Ugandan sample. As in the European samples female gender, living with one or no parent and number of direct events were related to PTSD symptomatology.

Four trauma types were endorsed in high numbers: childhood neglect (25.7\%), sexual abuse (15\%), death of someone close (75.5\%), and physical abuse (51\%). The latter was among the least frequently reported events in the European samples but was among the highest reported in Uganda. In Uganda, physical abuse was not associated with higher risk of meeting criteria for PTSD when other trauma and negative life events were controlled for, in contrast to threats of violence.

Corporal punishment in Ugandan schools was banned by a government circular in 2006. However, it is still widely practiced. Previous studies conducted in Uganda, specifically focusing on different types of physical abuse within the school setting, found much higher frequency rates. The latest ANPPCAN report [47] finds that $81 \%$ of children have been beaten at their school. Similarly, a Save the Children report [48] found that 98.3 percent reported having experienced physical violence, such as caning, slapping, pinching, locking up, or burning. The report further reveals that parents and teachers are reluctant to use the terms violence or abuse, when it comes to corporal punishment of children, rather it is perceived as a natural child-rearing practice. Also, domestic violence is highly prevalent with nearly $60 \%$ of women having experienced physical abuse and in $87 \%$ of those cases it is a husband or partner that was the perpetrator [49]. Indeed, the Western conceptualization of what constitutes physical abuse may not be applicable in many other parts of the world. For instance, in the 2006 mental health survey Uganda [50] 70.2\% of women was of the opinion that it can be justified that a husband uses violence against his wife in at least one of five presented instances (if she: burns the food, argues with him, goes out without telling him, neglects the children or refuses to have sexual intercourse with him).

It could be suggested that physical abuse would more likely be interpreted as threatening in a society, where it is uncommon compared to a society, where it is a common child rearing practice like Uganda. The understanding of what constitutes physical abuse in the various cultural contexts could hence explain both the relatively low reported frequency rates of physical abuse compared to other studies conducted in Uganda (simply because it is not viewed as abuse) but could also account for the difference between European samples and African samples in regards to subsequent development of PTSD. Of course, a more simple explanation could be that the severity of the maltreatment was less (starting later in life, lasting shorter, with few injuries). While logically reasonable, the abovementioned, well-documented reports give a picture of severe physical abuse (often combined with denial of food) as common means of upbringing children in Uganda.

Bullying has rarely been examined with regards to its relationship with PTSD. The few studies that have been conducted yield results that suggest that bullying although not in line with the DSM criteria for PTSD does significantly increase the risk of a PTSD diagnosis. In a Norwegian national sample of $8^{\text {th }}$ and $9^{\text {th }}$ graders it was found that $27.6 \%$ of boys and $40 \%$ of boys who had been bullied met criteria for PTSD [51]. Bullying could be 
perceived as more threatening in Uganda than in Europe due to the emphasis placed on family and group for survival. Hence alienation from a peer group could pose a greater threat to a Ugandan child than it would to children in more pluralistic societies. In line with this, Cluver et al. [52], in a study of 1050 children in deprived neighborhoods in South Africa, found that children victimized at home or in the community were at higher risk for being bullied. In light of these findings it is assumed that bullying is more likely to be perceived as a threat, as the majority of the bullied are already victimized.

Traffic accidents are quite often reported both as direct and indirect event and they were surprisingly associated with less PTSD in the Ugandan adolescents. Indeed, previous research finds that traffic accidents are less likely to precipitate PTSD compared to interpersonal and volatile traumas [53] [54]. The reason that at traffic accidents had this relationship with the subsequent development of PTSD in the Ugandan sample is not known. Maybe traffic accidents are associated with having more material resources or eliciting more social support because of the visibility and acceptability of this type of trauma compared to interpersonal traumas. Another explanation could be the lack of severity statements indicating how many times it has happened or the seriousness of the accident.

Surprisingly, rape was not significantly related to a PTSD diagnosis in the Ugandan sample, but sexual abuse was and indirect exposure to rape was. As for physical abuse, it could be carefully argued that subjects from collectivistic and individualistic cultures will differ in their appraisal of events and this could account for some of the differences between the samples, also regarding rape. Physical abuse, however is a common occurring phenomenon that is believed to be a vital component in the upbringing of children, rape is of course not. Another explanation could be found in the gender roles. In the 2006 Mental Health Survey [50], 26.3\% of women between 15 and 19 years of age indicated that husbands were justified in using physical violence if the wife refused to have sexual intercourse with him. If this belief, that men are entitled to sex within a marriage, also transcends to partners or even friends, and in addition is an expression of a societal belief in men's right to sexual intercourse with women; this could elicit different appraisals of rape, affecting the subsequent development of PTSD.

In a study of 172 female victims of rape, assault and robbery, peritraumatic responses and their relation with perceived threat was examined [55]. It was found that rape victims elicited more feelings of betrayal, fear, detachment, humiliation, numbness and dreamlike states, compared to victims of assault or robbery. In addition, rape victims, more often than robbery/assault victims, begged, pleaded or cried, tried to reason with the perpetrator, tried to struggle, keep quiet and do what they were told. It is likely that Ugandan women, if they indeed hold the belief that males has, at least to some extent a right to sex (and the right to resort to violence when denied sex), will experience some of these feelings to a lesser extent, and will be less likely to try to plead for the perpetrator to stop. The study concluded that peritraumatic emotions and responses accounted for more of the perception of threat than trauma type, and that especially the peritraumatic emotions and responses of rape victims were related to perceived threat [55]. The peritraumatic response to rape may hence explain some of the perceived threat and therefore lack of PTSD. It is likely that different perceptions of rape, rooted in cultural beliefs, could then account for some of the differences of trauma exposures predictive value on PTSD.

\subsection{Psychological Factors and Coping}

In accordance with our hypotheses emotional coping, negative affectivity, and somatization were contributing to predict the variability of PTSD severity. Rational coping was significantly associated with negative affectivity, but not with PTSD, somatization, or emotional coping. Emotional coping correlated strongly with all symptom measures, with total number of both direct and indirect events, with lower level of parental education and few daily meals. In the final regression analysis negative affectivity stands out as a very strong factor. Negative affectivity or neuroticism is related to coping efforts in general because it is associated with a heightened experience of distress and threat [56] and therefore am increased need for coping [57] However, because neurotic persons are easily overwhelmed by stress, they are very likely to seek to avoid stressors and decrease discomfort. Strong positive associations between negative affectivity/neuroticism and emotional coping and less strong but still significant to rational coping is found in other studies [58] [59].

Somatization is known to be a common state coexisting with PTSD. It is often consider a consequence of PTSD and to be associated with high levels of dissociation [60]. In a recent study [58], PTSD severity failed to predict somatization after negative affectivity was controlled for. The authors suggested that one possibility is that negative affectivity mediates the effect of PTSD on somatization. In the current study, however, that both 
somatization and negative affectivity independently contributed to PTSD severity.

\subsection{Cross Cultural Comparisons of Exposure to Traumatic Events and Development of PTSD}

Little attention has been given to the role culture plays with regards to appraisal in the PTSD research but this study lends support to understanding the conceptualization of what constitutes a trauma in a broader way. The appraisal of a given trauma will differ from individual to individual, but culture will play a part in that appraisal [61] [62] and hence subsequent development of PTSD. A major gap in the literature pertains to the difference between individualistic versus collectivistic cultures and their reactions to both direct and, not least, indirect trauma exposure.

It appears that other variables pertaining to the etiology and maintenance of PTSD symptoms are at play in this sample. Uganda represents a collectivistic culture which differs greatly from the individualistic in that the self-construct, in collectivistic cultures, is an interdependent entity and in individualistic cultures is perceived as an independent entity [63]. The Independent self-construct is defined by reference to internal thoughts, feelings and actions which are seen as independent variables and unique to the self. In contrast the interdependent selfconstruct is defined in reference to the connectedness to other people and as such, feelings thoughts and actions are determined and organized in relation to others and to situations.

Hence, the self-construct, in a collectivistic culture, is defined as a part of the group and the obligations to and needs of the group will be greater than to the individual. It could hence be argued that upon witnessing or hearing about a family member or close friends being exposed to a potentially traumatic event, would elicit greater distress, than it would actually experiencing it as the self-construct is more a product of the group rather than the individual. It could also be argued that a greater sense of guilt and failure would be elicited by indirect trauma exposure for an individual belonging to a collectivistic culture as opposed to an individual from an individualistic culture.

Where the differences in mean number of directly experienced events did not differ significantly between the European samples there was a significant difference with regards to exposure to indirect events between the samples. It hence seems that there is an association between number of indirectly experienced events and PTSD in the European studies - an association not present in the Ugandan study, as the hierarchical regression analysis demonstrates no effect of number of indirectly experienced events on PTSD in the final model. It could be speculated that the extent of direct exposure is so high in the Ugandan sample that the effect of indirect cumulative exposure is diminished.

\section{Conclusions}

As expected the Ugandan adolescents have experienced far more potentially traumatic events and negative life events than what has been documented in the similar European studies, subsequently there are also more PTSD cases. From the sample of 408 young Ugandans, $97.8 \%$ had been exposed to at least one potentially traumatic event and 37.7\% met diagnostic criteria for PTSD and an additional 28.2\% met a subclinical level. There was a significant gender difference with $30.5 \%$ of boys and $42.3 \%$ of girls meeting criteria. Female gender was also associated with higher levels of negative affect and somatization. Living without a parent was likewise a risk factor for exposure to negative life events, potentially traumatic events, PTSD and negative affect.

In general, the findings from the current study support findings from previous studies in other cultures and highlight the importance of appropriate coping skills and social support. Female gender, number of traumatic events, living with only one or no parent, somatization, negative affect and emotional coping were found to be associated with PTSD. Findings that were not in line with previous studies are the very few gender differences with regards to type of exposure with only rape, childhood neglect, and absence of a parent being experienced more by females than males. No single trauma had been experienced more often by males than females and no gender differences with regards to coping styles were found. It was also found, that specific potentially traumatic events, that normally holds great predictive value on PTSD, such as rape and physical abuse, did not yield similar results in the Ugandan sample. One explanation for this could relate to cognitive appraisals of these events.

The findings from this current research would seem to validate the application of the PTSD diagnosis in nonwestern countries. It may, however, lack some cultural sensitivity in the conceptualization of life threatening 
experiences and the list of traumatic events does not appear to be comprehensively enough to assess victimization in this Ugandan sample.

Among the implication of the study is that a high social priority should be given to children who are orphans or live with a single parent as their vulnerability stands out. It is also clear that Uganda is a country where many traumatic events and much violence have occurred and perhaps still is occurring resulting in high levels of trauma reactions. Pertaining community mental health, suicide prevention programs would be an investment as important as physical health. An important finding is the role of negative affectivity; in case a trauma focused intervention is not working well, one may consider focus on the negative affectivity itself to reduce post-trauma sequelae.

\section{Limitations}

The current study has number of limitations. The study is based on students self-reports, which could produce some response bias in regards to the students ability to be factual and honest and their willingness to remember painful events. Willis and Gonzales [64] have, however, shown that recognition in comparison with recall is less distressing when reporting a stressful event. The students were sitting very close to each other in the classrooms and this may have led to underreporting of events that represent some taboo in the Ugandan culture. It should also be noted that abortion as well as suicide are criminal offences in Uganda which could lead to underreport.

In order to facilitate a cross cultural comparison this study is a replica of studies carried out in European populations. Only $38.6 \%$ of males and $33.3 \%$ of females are enrolled in secondary education thus leaving out the vast majority of young Ugandans not enrolled in the school system. Because of language difficulties the data was gathered in three major cities, thus leaving out smaller cities and the large rural population. Despite the grade level, a compensatory, supportive data collection approach was applied. It would also be expected that cultural differences would make the list of 20 potentially traumatic events incomprehensive. There are widespread beliefs in witchcraft and possession by demonic powers in Uganda and exposure to these sorts of events could have been included in the list of potentially traumatic events. Indeed one of the subjects noted, in the comment section on the final page of the questionnaire that she believed to have been bewitched by her stepmother and as a consequence suffered from hallucinations at night.

Additionally, in the comment section on the final page, some of the children disclosed trauma exposure directly pertaining to lack of resources such as having to steal in order to eat or having to exchange sexual favors for school fees. This demonstrates that not only culture, but also living conditions necessitates a revision of Western produced trauma lists. These sorts of "self-inflicted" or "necessary" traumas are suspected to be almost exclusive to low-income countries and its associations with PTSD are, to our knowledge, not examined.

Another limitation of the study design is that it does not ask how many times a specific potentially traumatic event has happened. This would be relevant information in all the studies, but especially for the Ugandan sample where the frequency rates are so high, that it would be expected that the majority of the students have experienced the same potentially traumatic event more than once. In addition, it may have revealed gender differences to exposure. Finally, the measure of indirect exposure covers both witnessing, hearing of, or knowing someone who has been exposed. It is highly unlikely that the same response will be elicited upon witnessing versus hearing about a rape and makes it difficult to compare and analyze data with regards to the impact of indirect events on PTSD.

\section{References}

[1] Seides, R. (2010) Should the Current DSM-IV-TR Definition for PTSD Be Expanded to Include Serial and Multiple Microtraumas as Aetiologies? Journal of Psychiatric and Mental Health Nursing, 17, 725-731. http://dx.doi.org/10.1111/j.1365-2850.2010.01591.x

[2] Maschi, T., Baer, J., Morrissey, M.B. and Moreno, C. (2013) The Aftermath of Childhood Trauma on Late Life Mental and Physical Health: A Review of the Literature. Traumatology, 19, 49-64. http://dx.doi.org/10.1177/1534765612437377

[3] Seedat, S., Nyamai, C., Njenga, F., Vythilingum, B. and Stein, D.J. (2004) Trauma Exposure and Post-Traumatic Stress Symptoms in Urban African schools. British Journal of Psychiatry, 184, 169-175. http://dx.doi.org/10.1192/bjp.184.2.169

[4] Mels, C., Derluyn, I., Broekaert, E. and Rosseel, Y. (2009) Screening for Traumatic Exposure and Posttraumatic Stress 
Symptoms in Adolescents in the War-Affected Eastern Democratic Republic of Congo. Archives of Pediatrics and Adolescent Medicine, 163, 525-530. http://dx.doi.org/10.1001/archpediatrics.2009.56

[5] Karsberg, S.H. and Elklit, A. (2012) Victimization and PTSD in a Rural Kenyan Youth Sample. Clinical Practice \& Epidemiology in Mental Health, 8, 91-101. http://dx.doi.org/10.2174/1745017901208010091

[6] Harder, V.V., Mutiso, V.N., Khasakhala, L.I., Burke, H.H. and Ndetei, D.M. (2012) Multiple Traumas, Postelection Violence, and Posttraumatic Stress among Impoverished Kenyan Youth. Journal of Traumatic Stress, 25, 64-70. http://dx.doi.org/10.1111/j.1467-9450.2009.00728.x

[7] Domanskaite-Gota, V., Elklit, A. and Christiansen, D. (2009) Victimisation and PTSD in a Lithuanien National Youth Probability Sample. Nordic Psychology, 61, 66-81. http://dx.doi.org/10.1027/1901-2276.61.3.66

[8] Bödvarsdóttir, I. and Elklit, A. (2007) Victimisation and PTSD-like States in an Icelandic Youth Probability Sample. BMC Psychiatry, 7, 51. http://dx.doi.org/10.1186/1471-244X-7-51

[9] Petersen, T., Elklit, A. and Gytz Olesen, J. (2010) Victimisation and PTSD in a Faroese Youth Total-Population Sample. Scandinavian Journal of Psychology, 51, 56-62. http://dx.doi.org/10.1111/j.1467-9450.2009.00728.x

[10] Elklit, A. (2002) Victimisation and PTSD in a Danish National Youth Probability Sample. Journal of the American Academy of Child \& Adolescent Psychiatry, 41, 174-181. http://dx.doi.org/10.1097/00004583-200202000-00011

[11] Bayer, C.P., Klasen, F. and Adam, H. (2007) Association of Trauma and PTSD Symptoms with Openness to Reconciliation and Feelings of Revenge among Former Ugandan and Congolese Child Soldiers. JAMA, 298, 555-559. http://dx.doi.org/10.1001/jama.298.5.555

[12] Okello, J., Onen, T.S. and Musisi, S. (2007) Psychiatric Disorders among War-Abducted and Non-Abducted Adolescents in Gulu District, Uganda: A Comparative Study. African Journal of Psychiatry, 10, 225-231.

[13] Rasmussen, D.J., Karsberg, S., Karstoft, K.-I. and Elklit, A. (2013) Victimization and PTSD in an Indian Youth Sample from Pune City. Open Journal of Epidemiology, 3, 12-19. http://dx.doi.org/10.4236/ojepi.2013.31003

[14] Sack, W.H., Seeley, J.R. and Clarke, G.N. (1997) Does PTSD Transcend Cultural Barriers? A Study from the Khmer Adolescent Refugee Project. Journal of the American Academy of Child \& Adolescent Psychiatry, 36, 49-54. http://dx.doi.org/10.1097/00004583-199701000-00017

[15] Mehta, K., Vankar, G. and Patel, V. (2005) Validity of the Construct of Post-Traumatic Stress Disorder in a Low-Income Country. British Journal of Psychiatry, 187, 585-586. http://dx.doi.org/10.1192/bjp.187.6.585

[16] UNFPA: Population Secretariat (POPSEC) Uganda (2012) State of the Uganda Population Report 2012. http://mail2.unfpa.or.ug/pub/2012/2012 SUPRE.pdf

[17] Lazarus, R.S. and Folkman, S. (1984) Stress, Appraisal, and Coping. Springer, New York.

[18] Patterson, J.M. and McCubbin, H.I. (1987) Adolescent Coping Style and Behaviors: Conceptualization and Measurement. Journal of Adolescence, 10, 163-186. http://dx.doi.org/10.1016/S0140-1971(87)80086-6

[19] Carver, C.S. and Connor-Smith, J.K. (2010) Personality and Coping. Annual Review of Psychology, 61, 679-704. http://dx.doi.org/10.1146/annurev.psych.093008.100352

[20] Plancherel, B., Bolognini, M. and Halfon, O. (1998) Coping Strategies in Early and Mid-Adolescence: Differences According to Age and Gender in a Community Sample. European Psychologist, 3, 192-201. http://dx.doi.org/10.1027/1016-9040.3.3.192

[21] Bödvarsdóttir, I. and Elklit, A. (2004) Psychological Reactions in Icelandic Earthquake Survivors. Scandinavian Journal of Psychology, 45, 3-13. http://dx.doi.org/10.1111/j.1467-9450.2004.00373.x

[22] Watson, D. and Clark, L.A. (1984) Negative Affectivity: The Disposition to Experience Aversive Emotional States. Psychological Bulletin, 96, 465-490.

[23] Petersen, T., Armour, C. and Elklit, A. (2013) Modelling Patterns of Negative Life Experiences and Mental Health in Faroese Adolescents. Scandinavian Journal of Child and Adolescent Psychiatry, 1, 63-71.

[24] Escalona, R., Achilles, G., Waitzkin, H. and Yager, J. (2004) PTSD and Somatization in Women Treated at a VA Primary Care Clinic. Psychosomatics, 45, 291-296. http://dx.doi.org/10.1176/appi.psy.45.4.291

[25] North, C.S., Kawasaki, A., Spitznagel, E.L. and Hong, B. (2004) The Course of PTSD, Major Depression, Substance Abuse, and Somatization after a Natural Disaster. Journal of Nervous \& Mental Disease, 192, 823-829. http://dx.doi.org/10.1097/01.nmd.0000146911.52616.22

[26] Katon, W., Sullivan, M. and Walker, E. (2001) Medical Symptoms without Identified Pathology: Relationship to Psychiatric Disorders, Childhood and Adult Trauma, and Personality Traits. Annals of Internal Medicine, 134, 917-925. http://dx.doi.org/10.7326/0003-4819-134-9_Part_2-200105011-00017

[27] Balvig, F. (1999) RisikoUngdom. Ungdomsundersøgelse. DetkriminalpræventiveRåd, Copenhagen.

[28] Rogers, D., Jarvis, G. and Najarian, B. (1993) Detachment and Coping: The Construction and Validation of a New 
Scale for Measuring Coping Strategies. Personality and Individual Differences, 15, 619-626. http://dx.doi.org/10.1016/0191-8869(93)90003-L

[29] Elklit, A. (1996) Coping Styles Questionnaire: A Contribution to the Validation of a Scale for Measuring Coping Strategies. Personality and Individual Differences, 21, 809-812. http://dx.doi.org/10.1016/0191-8869(96)00123-7

[30] Mollica, R.F., Caspi-Yavin, Y., Bollini, P., Truong, T., Tor, S. and Lavelle, J. (1992) The Harvard Trauma Questionnaire: Validating a Cross-Cultural Instrument for Measuring Torture, Trauma and Posttraumatic Stress Disorder in Indochinese Refugees. Journal of Nervous \& Mental Disease, 180, 111-116. http://dx.doi.org/10.1097/00005053-199202000-00008

[31] American Psychiatric Association (2000) DSM-IV-TR. Author, Washington DC.

[32] Briere, J. and Runtz, M. (1989) The Trauma Symptom Checklist (TSC-33): Early Data on a New Scale. Journal of Interpersonal Violence, 4, 151-163. http://dx.doi.org/10.1177/088626089004002002

[33] Krog, T. and Duel, M. (2003) Trauma Symptom Checklist (TSC). Psykologisk Studieskriftserie, 6, 1-162.

[34] Hanson, R.F., Borntrager, C., Self-Brown, S., Kilpatrick, D.G., Saunders, B.E., et al. (2008) Relations among Gender, Violence Exposure, and Mental Health: The National Survey of Adolescents. American Journal of Orthopsychiatry, 78, 313-321.

[35] Buka, S.L., Stichick, T.L., Birdthistle, I. and Earls, F.J. (2001) Youth Exposure to Violence Prevalence Risks and Consequences. American Journal of Orthopsychiatry, 71, 298-310.

[36] Foster, F.D., Kuperminc, G.B. and Price, A.V. (2004) Gender Differences in Posttraumatic Stress and Related Symptoms in among Inner-City Minority Youth Exposed to Community Violence. Journal of Youth and Adolescence, 33, 59-69. http://dx.doi.org/10.1023/A:1027386430859

[37] O’Donnell, D.A., Roberts, W.C. and Schwab-Stone, M.E. (2011) Community Violence Exposure and Posttraumatic Stress Reactions among Gambian Youth: The Moderating Role of Positive School Climate. Social Psychiatry and Psychiatric Epidemiology, 46, 59-67. http://dx.doi.org/10.1007/s00127-009-0162-X

[38] Broderick, P.C. (1998) Early Adolescent Gender Differences in the Use of Ruminative and Distracting Coping Styles. The Journal of Early Adolescence, 18, 173-191. http://dx.doi.org/10.1177/0272431698018002003

[39] Matud, M.P. (2004) Gender Differences in Stress and Coping Styles. Personality and Individual Differences, 37, 14011415. http://dx.doi.org/10.1016/j.paid.2004.01.010

[40] Kaiseler, M., Polman, R.C.J. and Nicholls, A.R. (2012) Gender Differences in Appraisal and Coping: An Examination of the Situational and Dispositional Hypothesis. International Journal of Sport Psychology, 43, 1-14.

[41] Schumm, J.A., Briggs-Phillips, M. and Hobfoll, S.E. (2006) Cumulative Interpersonal Traumas and Social Support as Risk and Resiliency Factors in Predicting PTSD and Depression among Inner-City Women. Journal of Traumatic Stress, 19, 825-836. http://dx.doi.org/10.1002/jts.20159

[42] Holeva, V., Tarrier, N. and Wells, A. (2001) Prevalence and Predictors of Acute Stress Disorder and PTSD Following Road Traffic Accidents: Thought Control Strategies and Social Support. Behavior Therapy, 32, 65-83. http://dx.doi.org/10.1016/S0005-7894(01)80044-7

[43] Ullman, S.E., Townsend, S.M., Filipas, H. and Starzynski, L. (2007) Structural Models of the Relations of Assault Severity, Social Support, Avoidance Coping, Self-Blame and PTSD among Sexual Assault Survivors. Psychology of Women Quarterly, 31, 23-37. http://dx.doi.org/10.1111/j.1471-6402.2007.00328.x

[44] Siedlecki, K.L., Salthouse, T.A., Oishi, S. and Jeswani, S. (2014) The Relationship between Social Support and Subjective Wellbeing across Age. Social Indicators Research, 117, 561-576.

[45] Brannan, D., Biswas-Diener, R., Mohr, C.D., Mortazavi, S. and Stein, N. (2013) Friends and Family: A Cross-Cultural Investigation of Social Support and Subjective Well-Being among College Students. The Journal of Positive Psychology, 8, 65-75. http://dx.doi.org/10.1080/17439760.2012.743573

[46] Lakey, B. and Tanner, S.M. (2013) Social Influences in Negative Thinking and Affect. Cognitive Therapy and Research, 37, 160-172. http://dx.doi.org/10.1007/s10608-012-9444-9

[47] ANPPCAN: African Network for the Prevention and Protection against Child Abuse and Neglect (2011) Baseline Survey on Violence against Children in Uganda. http://www.anppcanug.org/wp-content/uploads/research_reports/Violence_Against_Children_in_schools_2011.pdf

[48] Naker, D. (2005) Violence against Children-The Voices of Ugandan Children and Adults. http://raisingvoices.org/wp-content/uploads/2013/03/downloads/resources/violence against children.pdf

[49] UNFPA Uganda Country Office Annual Report 2012. http://mail2.unfpa.or.ug/pub/2012/Reports/2012UNFPAUG_COReportHeavy.pdf

[50] UBOS: Uganda Bureau of Statistics (2007) Uganda Demographic and Health Survey 2006. http://www.measuredhs.com/pubs/pdf/FR194/FR194.pdf 
[51] Idsoe, T., Dyregrov, A. and Cosmovici, E. (2012) Bullying and PTSD Symptoms. Journal of Abnormal Child Psychology, 40, 901-911. http://dx.doi.org/10.1007/s10802-012-9620-0

[52] Cluver, L., Bowes, L. and Gardner, F. (2010) Risk and Protective Factors for Bullying Victimization among AIDS-Affected and Vulnerable Children in South Africa. Child Abuse \& Neglect, 34, 793-803. http://dx.doi.org/10.1016/j.chiabu.2010.04.002

[53] Frans, O., Rimmö, P.A., Åberg, L. and Fredrikson, M. (2005) Trauma Exposure and Post-Traumatic Stress Disorder in the General Population. Acta Psychiatrica Scandinavica, 111, 291-299. http://dx.doi.org/10.1111/j.1600-0447.2004.00463.x

[54] Saul, A.L., Grant, K.E. and Carter, J.C. (2008) Post-Traumatic Reactions in Adolescents: How Well Do the DSM-IV PTSD Criteria Fit the Real Life Experience of Trauma Exposed Youth? Journal of Abnormal Child Psychology, 36, 915-925. http://dx.doi.org/10.1007/s10802-008-9222-z

[55] Kaysen, D., Morris, M.K., Rizvi, S.L. and Resick, P.A. (2005) Peritraumatic Responses and Their Relationship to Perceptions of Threat in Female Crime Victims. Violence against Women, 11, 1515-1535.

[56] Costa, P.T., Somerfeld, M.R. and McCrae, R.R. (1996) Personality and Coping: A Reconceptualization. In: Zeidner, M. and Endler, N.S., Eds., Handbook of Coping: Theory, Research, Applications, Wiley, Oxford, 44-61.

[57] Kardum, I. and Krapić, N. (2001) Personality Traits, Stressful Life Events, and Coping Styles in Early Adolescence. Personality and Individual Differences, 30, 503-515. http://dx.doi.org/10.1016/S0191-8869(00)00041-6

[58] Christiansen, D.M., Hansen, M. and Elklit, A. (2014) Correlates of Coping Styles in an Adolescent Trauma Sample. Journal of Child \& Adolescent Trauma, 7, 75-85.

[59] Watson, D. and Hubbard, B. (1996) Adaptational Style and Dispositional Structure: Coping in the Context of the FiveFactor Model. Journal of Personality, 64, 737-774. http://dx.doi.org/10.1111/j.1467-6494.1996.tb00943.x

[60] Kolk, V.D., Pelcovitz, D., Roth, S., Mandel, F.S., McFarlane, A. and Herman, J.L. (1996) Dissociation, Somatization, and Affect Dysregulation: The Complexity of Adaptation to Trauma. American Journal of Psychiatry, 153, 83-93.

[61] Jobson, L. and O’Kearney, R.T. (2009) Impact of Cultural Differences in Self on Cognitive Appraisals in Posttraumatic Stress Disorder. Behavioral and Cognitive Psychotherapy, 37, 249-266. http://dx.doi.org/10.1017/S135246580900527X

[62] Sato, T. (2001) Autonomy and Relatedness in Psychopathology and Treatment: A Cross-Cultural Formulation. Genetic Social and General Psychology Monographs, 127, 89-127.

[63] Markus, H.R. and Kitayama, S. (1991) Culture and the Self: Implications for Cognition, Emotion, and Motivation. Psychological Review, 98, 224-253.

[64] Willis, G.B. and Gonzales, A. (1998) Methodological Issues in the Use of Survey Questionnaires to Assess the Health Effects of Torture. Journal of Nervous \& Mental Disease, 186, 283-289. http://dx.doi.org/10.1097/00005053-199805000-00004 
Scientific Research Publishing (SCIRP) is one of the largest Open Access journal publishers. It is currently publishing more than 200 open access, online, peer-reviewed journals covering a wide range of academic disciplines. SCIRP serves the worldwide academic communities and contributes to the progress and application of science with its publication.

Other selected journals from SCIRP are listed as below. Submit your manuscript to us via either submit@scirp.org or Online Submission Portal.
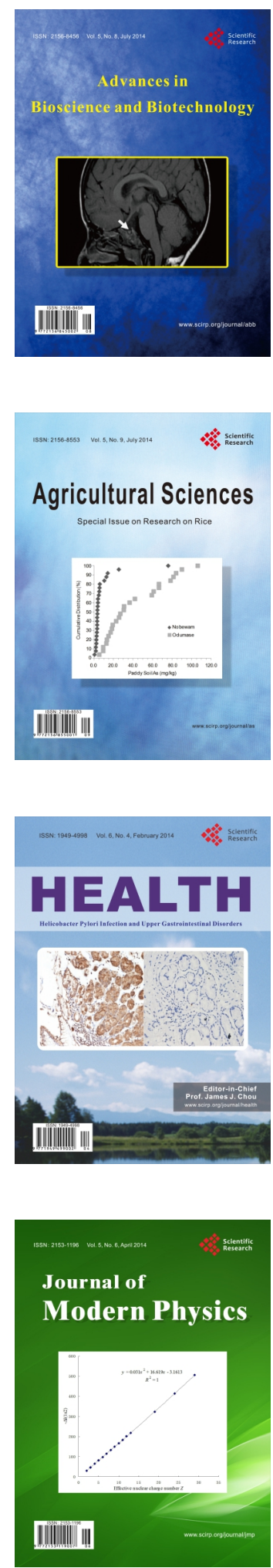
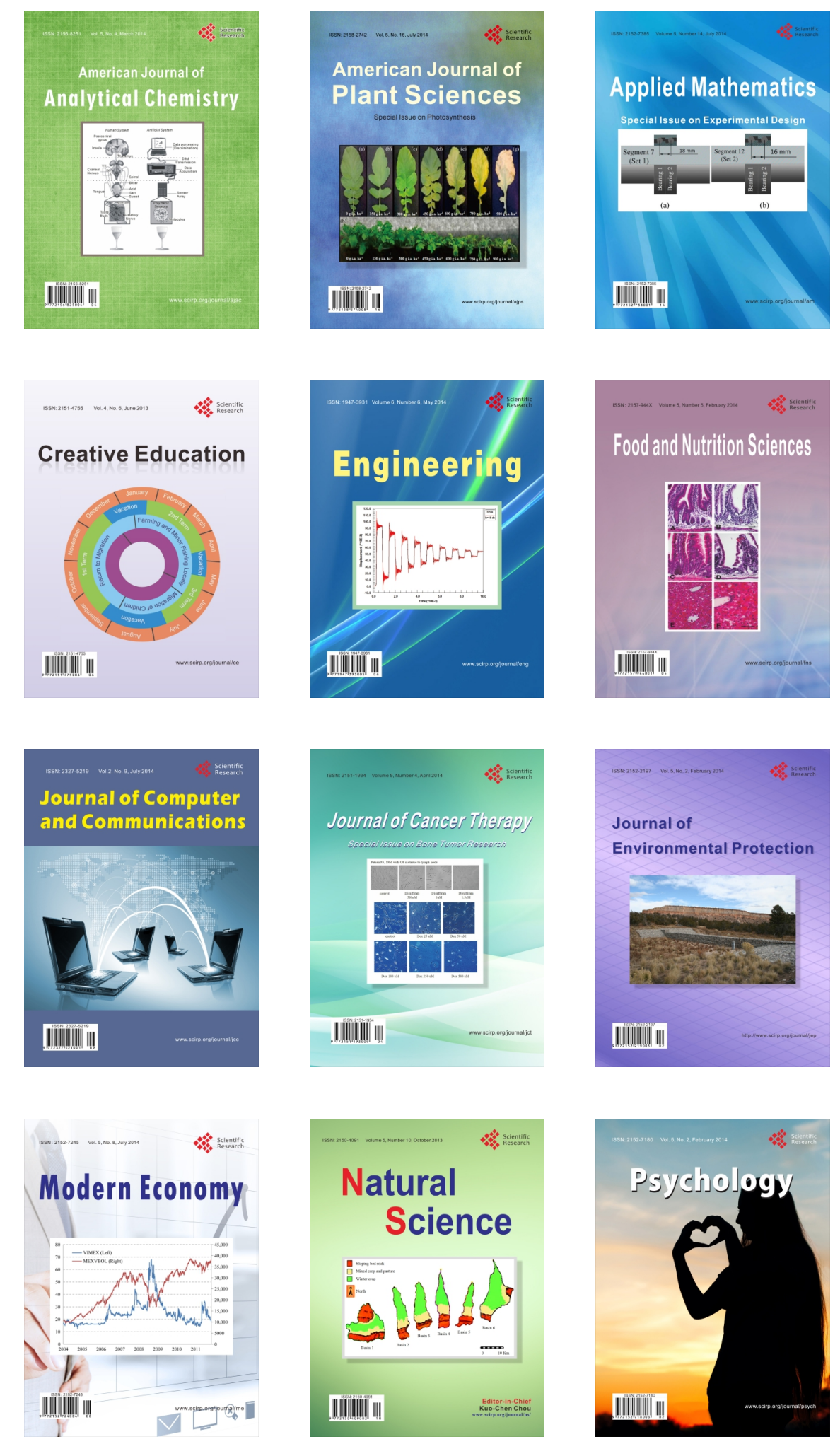